\title{
Mechanical properties of soil buried kenaf fibre reinforced thermoplastic polyurethane composites
}

\begin{abstract}
A study on mechanical properties of soil buried kenaf fibre reinforced thermoplastic polyurethane (TPU) composites is presented in this paper. Kenaf bast fibre reinforced TPU composites were prepared via melt-mixing method using Haake Polydrive R600 internal mixer. The composites with $30 \%$ fibre loading were prepared based on some important parameters; i.e. $190{ }^{\circ} \mathrm{C}$ for reaction temperature, $11 \mathrm{~min}$ for reaction time and $400 \mathrm{rpm}$ for rotating speed. The composites were subjected to soil burial tests where the purpose of these tests was to study the effect of moisture absorption on the mechanical properties of the composites. Tensile and flexural properties of the composites were determined before and after the soil burial tests for 20,40,60 and 80 days. The percentages of both moisture uptake and weight gain after soil burial tests were recorded. Tensile strength of kenaf fibre reinforced TPU composite dropped to $\sim 16.14 \mathrm{MPa}$ after 80 days of soil burial test. It was also observed that there was no significant change in flexural properties of soil buried kenaf fibre reinforced TPU composite specimens.
\end{abstract}

Keyword: Soil buried kenaf fibre; Thermoplastic polyurethane; Kenaf bast fibres 